This item was submitted to Loughborough's Research Repository by the author.

Items in Figshare are protected by copyright, with all rights reserved, unless otherwise indicated.

\title{
Developing performance using rational emotive behavior therapy (REBT): a case study with an elite archer
}

\section{PLEASE CITE THE PUBLISHED VERSION}

https://doi.org/10.1123/tsp.2015-0083

\section{PUBLISHER}

(c) Human Kinetics

\section{VERSION}

AM (Accepted Manuscript)

\section{PUBLISHER STATEMENT}

This work is made available according to the conditions of the Creative Commons Attribution-NonCommercialNoDerivatives 4.0 International (CC BY-NC-ND 4.0) licence. Full details of this licence are available at: https://creativecommons.org/licenses/by-nc-nd/4.0/

\section{LICENCE}

CC BY-NC-ND 4.0

\section{REPOSITORY RECORD}

Wood, Andrew G., Jamie Barker, and Martin J. Turner. 2017. "Developing Performance Using Rational Emotive Behavior Therapy (REBT): A Case Study with an Elite Archer". figshare. https://hdl.handle.net/2134/28289. 
Running head: REBT IN SPORT

1

2

3

4

5

6

7

8

9

10

11

12

13

14

15

16

17

18

19

20

21

22

23

24

25

26

27

28 With an Elite Archer.

$26 / 05 / 2016$

Developing Performance Using Rational Emotive Behavior Therapy (REBT): A Case Study 


\section{Abstract}

Rational Emotive Behavior Therapy (REBT; Ellis, 1957) is a psychotherapeutic approach receiving increasing interest within sport. REBT is focused on identifying, disputing and replacing Irrational Beliefs (IBs) with Rational Beliefs (RBs) to promote emotional wellbeing and goal achievement. This study provides a detailed case outlining the application and effect of seven one-to-one REBT sessions with an elite level archer who was experiencing performance-related anxiety, prior to and during competition. The case also offers an insight into common misconceptions, challenges and guidance for those who may consider applying

37 REBT within their practice. Data revealed meaningful short and long -term (6-months) reductions in IBs and improvements in RBs, self-efficacy, perception of control and archery performance. The case supports the effective application of REBT as an intervention with athletic performers, promoting lasting changes in an athlete's ability to manage their cognitions, emotions and behaviors in the pursuit of performance excellence. 


\section{Developing Performance Using Rational Emotive Behavior Therapy (REBT): A Case}

\section{Study With an Elite Archer.}

\section{Introduction}

The reported use of Rational Emotive Behavior Therapy (REBT; Ellis, 1957) with athletes is fast emerging within the sport psychology literature. Recent research has yielded promising findings, but there still exists scant research documenting and detailing the application of REBT with athletes (Turner \& Barker, 2014). REBT is a psychotherapeutic approach established by Albert Ellis in 1955. Its philosophy is outlined by an ancient maxim stating "men are not disturbed by things, but by the view which they take of them " (Epictetus, 55135 A.D.). REBT emphasizes it is one's Irrational Beliefs (IBs) about adversity that leads to dysfunctional and unhelpful, emotions, behaviors, and cognitive consequences; whereas, Rational Beliefs (RBs) lead to functional and helpful alternatives. These beliefs consist of four core beliefs each comprising of one primary and three secondary beliefs (Digiuseppe, Doyle, Dryden, \& Backx, 2013). The primary core irrational belief is a "rigid and extreme demand" followed by three secondary beliefs of, "awfulizing", "low frustration tolerance", and "self/other/life-depreciation". In contrast, primary rational beliefs are a "flexible and a non-extreme preference" followed by three secondary beliefs of, "anti-awfulizing", "high frustration tolerance', and "self/other/life acceptance" (Digiuseppe et al.). IBs are dogmatic, inflexible, inconsistent with social reality and hinder long-term goal attainment, instead RBs are helpful, flexible, consistent with social reality and help long-term goal attainment. Research suggests that in the face of adversity, IBs leads to dysfunctional and unhealthy negative emotions (e.g., anger, anxiety, depression) that are associated with maladaptive behaviors (e.g., avoidant and/or escape-based behaviors); whereas RBs generate functional and healthy negative emotions (e.g., annoyance, concern, sadness) that facilitate adaptive 
behaviors (e.g., problem-solving-based behaviors), the latter being more helpful towards the attainment of goals than the former (David, Szentagotai, Eva, \& Macavei, 2005; Dryden, 2002). The efficacy of REBT in dealing with psychological health has been validated through meta-analyses (e.g., Engles, Garnefski, \& Diekstra, 1993; Lyons \& Woods, 1991), establishing REBT as an effective model of human functioning.

Although scant, early REBT researchers reported the promising effects of REBT on athletic performance (e.g., Bernard, 1985; Elko \& Ostrow, 1991). Most recently, a line of research systematically investigating the effects of REBT on athletic performance has emerged. To illustrate, a study by Larner, Morris, and Marchant, (2007) reported that reductions in IBs and increases in RBs decreased the negative directional interpretation of anxiety experienced by athletes. Furthermore, elite youth cricketers reported reductions in IBs and cognitive anxiety after receiving three, one-to-one REBT sessions (e.g., Turner \& Barker, 2013). Using a workshop-based modality, elite soccer academy athletes reported short-term reductions in IBs after receiving a single REBT workshop (e.g., Turner et al., 2014a), as well as long-term reductions in IBs after receiving multiple REBT workshops (e.g., Turner, Slater \& Barker, 2014b). Collectively, research demonstrates the potential of REBT to develop important psychological outcomes relative to athletic performance. However, to date this research has not used objective markers of performance to better ascertain the effects of REBT on athletic performance.

All humans have a propensity for both rational and irrational beliefs, where individual differences are buffered by biological traits and cultural/educational influences (Neenan \& Dryden, 2004). The dysfunctional and maladaptive responses associated with IBs are magnified within sport where athletes are expected to thrive when encountering competitive, organizational, and personal stressors in pursuit of performance excellence (Weston, Thelwell, Bond, \& Hutchings, 2009). An athletes' inherent fixation upon success and failure, 
perceived self-worth, and an experience of high quality treatment may encourage an irrational shift from "want to" to "have to" (Botterill, 2005). REBT aims to facilitate profound change in one's thinking, feelings, and behaviors, shifting from an irrational to a rational philosophy that addresses the root cause of a symptomatic issue. Ultimately, a rational philosophy accelerates an individual's recovery from failure towards constructive goal directed actions. Research suggests that individuals' beliefs are comparable to that of a primary appraisal (Lazarus, 1991), hereby, influencing an individual's particular representation of reality (Hyland \& Boduszek, 2012). Therefore, irrespective of the adversity, athletes have autonomy over their emotional and behavioral response (i.e., functional/helpful vs. dysfunctional/unhelpful responses; Dryden \& Neenan, 2015). It is both unrealistic and unhelpful to expect an athlete to respond indifferently, or with immediate positivity after experiencing an adversity (e.g., failed selection), instead REBT encourages a healthy negative response (Dryden \& Neenan). Within the anxiety-performance literature the regulatory subcomponent of the three-dimensional model (Cheng, Hardy, \& Markland, 2009) re-conceptualizes and supports the adaptive vs. maladaptive distinction in negative emotions. Explicitly, athlete's perceived control to cope and attain goals under stress is proposed to influence both the intensity and adaptive quality of anxiety. For example, an athlete who holds IBs will feel highly anxious (dysfunctional emotion) before a major competition because the prospect of failing will conflict with their primary belief of demanding success (e.g., "I would like to win, therefore I absolutely must") and irrationally reinforcing their secondary beliefs of awfulizing, and self-depreciation (e.g., "if I do not win, it would be awful and therefore this would make me a complete failure"). An athlete would then place greater demands on themselves, in turn reducing their perception of control and coping. Whereas, an athlete with RBs will feel concerned (functional emotion) because the prospect of failing will to a lesser extent conflict with their preference for success (e.g., I really want to 
win), thus, reinforcing their secondary beliefs of anti-awfulizing and self-downing (e.g., "if I am not successful, it is not awful and it doesn't mean I am a complete failure, instead I have only failed this time"; Turner \& Barker, 2014). Athletes with RBs will place less demand on themselves and experience a greater perception of control.

The investigation of REBT and sporting performance whilst emerging remains sparse (Turner \& Barker, 2014), additionally there exists no case study documenting the application of REBT with an elite athlete. The value of case studies for sport psychologists has been brought to recent attention, providing a beneficial insight into the application, influence, and effects of sport psychology interventions (Giges \& Van Raalte, 2012). The primary aim of this study was to contribute to the growing body of research evidencing the application and effects of REBT practice with athletes in managing performance related issues. This case provided a detailed practitioner account and an athletes experience throughout the entirety of an REBT program, informing sport psychology practitioners looking to adopt REBT within their practice. The case also detailed the application of typical and novel techniques, common misconceptions, and challenges faced when intervening using REBT with an athlete. The participant provided informed consent to undertake the research and institutional ethics approval was granted for the procedures of the study.

\section{Needs Analysis}

Zara (Pseudonym) was a 44-year-old nationally ranked elite level archer who had been competing in archery at this level for 4 years, representing both county and district teams. Zara trained four days a week split between the local and regional archery centers. Initially, a meeting was organized with Zara by the consultancy team (lead and second author). The use of consultancy teams has been advocated as an effective way of developing the consultancy process and supporting the training of neophyte and current sport psychology 
practitioners (Pitt et al., 2015). During the initial contact with Zara she presented exaggerated bouts of anxiety prior to and during competition, which was having a detrimental effect upon her performance. In addition, these dips in performance were exemplified during indoor archery competitions that Zara considered the easier format compared to outdoor competition (e.g., less extraneous variables, shorter distance, greater margin of error). To compound this issue, Zara felt she did not have control or was able to regulate her emotions when encountering challenging situations (i.e., recovering her form). To investigate further we administered the Shortened General Attitudes and Belief Scale (SGABS: Lindner, Kirkby, Wertheim, \& Birch, 1999), in turn indicating the presence of high IBs and low RBs (Lindner et al., 1999). Upon further correspondence it became apparent that when Zara perceived low expectations from herself and others (i.e., difficult competition, a longer shooting range, competing against superior opponents) her performance thrived, whereas when the expectation to be successful was elevated (i.e., indoor competition, relatively novice opponents, and perfect conditions) her performance suffered. The following extract was taken from email correspondence where Zara commented on feelings similar to that of "the end of the world", after her form during a competition took an unexpected decline. Such a statement is indicative of the extreme and unhelpful beliefs commonly associated with REBT, in turn leading to unhealthy emotions and maladaptive behaviors.

" 60 arrows in the morning were good and then the 60 in the afternoon were not
as good. Some arrows went wayward and I even had a miss. This made me feel
quite sick to my stomach because I felt I was doing the same form etc. I told
another archer who said 'it's not the end of the world' but it kind of felt like that
to me. I checked my equipment; it was fine so it must have been me. Other
archers were puzzled and seem astonished that my arrows could be so off"
This discrepancy in performance and psychological control between outdoor and indoor competitions suggested Zara could be harboring an irrational approach to failure and success underpinned by demands instead of asserted preferences (Dryden, 2009). Zara was 
experiencing a somewhat common paradox within high performance sport; the more she demanded success the harder it became for her to attain. Information collated from the needs analysis provided sufficient justification that the application of REBT would provide an appropriate intervention for Zara's case (see Turner \& Barker, 2014).

\section{The Application of REBT}

The central purpose of REBT is to actively challenge and dispute the client's irrational philosophy and replace it with an effective new rational alternative. REBT is proposed to be at its most effective on a one-to-one basis, over a series of sessions. The lead author was a supervised trainee Sport and Exercise Psychologist registered within the Division of Sport and Exercise Psychology (DSEP), an accredited primary practitioner in REBT, and delivered the seven one-to-one REBT sessions with Zara. Each session lasted for approximately 60 minutes and was conducted over a 3-month period. The REBT intervention was separated into education, disputation, and reinforcement phases, guided by the ABCDE framework (see Figure 1). For an overview of applying REBT in sport see Turner and Barker (2014).

\section{Education Phase}

The education phase aimed to teach the client that it is their beliefs (B) that determine their emotional and behavioral consequences (C), rather than the adversity alone (A) (Dryden \& Branch, 2008). Here, an emphasis was placed on ownership and control over Zara's emotional and behavioral response. Thus, irrespective of the adversity (A), Zara would gain autonomy over the functionality of her emotions and behaviors through the alteration of her beliefs (B). Before addressing the beliefs (B), Zara was asked to outline how she would like to respond (C), a response that would be helpful in the pursuit of her goal of performing well. Therefore, instead of feeling extremely anxious (dysfunctional emotion) Zara wanted to feel nervous (functional), display behaviors that were adaptive in regaining her form, and 
202

203

204

205

206

207

208

209

210

211

212

213

214

215

216

217

218

219

ultimately, revert back to her previous form. The following transcript examples the process involved in eliciting IBs:

Practitioner: What are you telling yourself about the situation (A), which leads you to feel and act like this (C)?

Zara: That I should be scoring higher, especially during easy indoor competitions

Practitioner: Why is it that should you be scoring higher?

Zara: Because I can shoot a lot better than I was shooting, especially during indoor shoots. I just have to shoot better than I do outdoors.

Practitioner: Would it be fair to say that because you would like to perform well when you expect to do so, that you believe you have to.

This led to establishing the irrational belief: "I would like to perform well when I compete in relatively easy competitions, therefore I must, if not it would be awful, and this would be unbearable for me". Such a process is then repeated with other challenging situations encountered. Throughout the education phase the client's emotional responsibility was emphasized, highlighting the B (Belief) - C (Consequence) connection, rather than the adversity (A) being solely responsible for her response (Dryden \& Neenan, 2015). To reinforce Zara's self-awareness an ABC diary was provided as an inter-session task (Ellis \& Dryden, 1997). During this phase, it was important to consider factors that influenced the practitioner-client relationship that facilitated the receipt of REBT. From the outset, Zara's expectations and goals were addressed and regularly reviewed. Throughout the intervention it was important for the practitioner to consider catering the pace of the sessions, interpersonal style (e.g., level of disclosure, humor, formality), and matching the influence base (e.g., expertise, likeability) to Zara's preference (Dryden \& Neenan, 2015). The education phase developed Zara's self-awareness, moreover it provided the building blocks to access and dispute her core IBs, which can be difficult to access, and stubborn to change. (Neenan \& Dryden, 2004). At its early conception REBT was mainly an active-directive therapy. However, contemporary advocates consider that as the REBT intervention progresses, to encourage an active and self-directed client (Dryden \& Neenan, 2015). 


\section{Disputation Phase}

The disputation phase was the most critical aspect of the REBT intervention and took place over three sessions. Practitioners have typically advised that each session is 45 minutes or longer in a three -session schedule, to ensure a comprehensive disputation process (Dryden \& Neenan, 2015; Turner \& Barker, 2014).

Disputing an individual's belief is a challenging and sensitive process. Therefore it was important for the practitioner to manage the levels of humor (Sultanoff, 2013), as well as including elements of practitioner self-disclosure, to help normalize Zara's position (Peterson, 2002). Adopting an ABCDE model, the practitioner rather than disputing the adversity (A), disputed (D) Zara's existing IBs (B) and strengthened her new effective (E) RBs, thus promoting healthy emotions, and adaptive behaviors (Ellis \& Dryden, 1997). REBT acknowledges that the adversity (A) is assumed to be true and for the time being accept that it cannot be altered. The intervention provides an elegant solution instead of an immediate practical solution allowing the client to better manage and respond adaptively in any situation that arises, thus promoting long-term fundamental changes. To illustrate, when Zara became increasingly anxious of her 'poor' performance scores, REBT would not challenge possible misperceptions over whether it was a poor performance (A). Instead, through the promotion of her RBs (B) about that situation, REBT would facilitate a helpful emotion allowing Zara to respond in an adaptive manner. The following extract from Zara provides an example of an analogy that helped Zara to understand this process:

"We spoke of "minimizing the dip", so the recovery time is quicker and is a more helpful response, instead of having a total flip out with several more errors after those six, and it worked and you know minimize that and it works."

From the onset of the disputation phase it was important for the practitioner to manage Zara's expectations and highlight the challenging nature of the disputation phase. To avoid confusion and ensure a comprehensive disputation process the practitioner used a directive 
and formulaic approach to dispute Zara's IBs, starting with the most significant: "I would like to perform well when I compete in relatively easy competitions, therefore I must, if not it would be awful and this would be unbearable for me". This process involved three strategies based upon evidence, logic, and pragmatics (DiGiuseppe, 1991). The following transcript outlines the initial disputation process, referring to evidence, logic, and pragmatics.

Practitioner: What evidence is there that you have to perform to your potential when you compete in easy competitions?

Client: Well if I know I can shoot that well, I have to.

Practitioner: Where is the evidence that because you expect to do so, that you have to shoot well?

Practitioner: What do you think about the belief, because you expect to perform well that you absolutely must?

Client: Well that would make sense to me.

Practitioner: Is this logical that because you want something that you must have it?

Client: That is what drives me on, I have to perform well.

Practitioner: Has there ever been a time where you wanted something but was unable to attaint it?

Practitioner: How helpful is thinking that you have to perform well?

Client: Well that should be helpful for me.

Practitioner: How helpful has this belief been for your short and long-term goals?

This disputation process was then repeated with Zara's awfulizing belief (e.g., it would be awful) and low-frustration tolerance belief (e.g., "this would be unbearable for me"). As exampled, Socratic questioning was adopted, in which the practitioner asked a series of progressive and open questions that encouraged self-reflection (Dryden \& Branch, 2008). As the disputation unfolded Zara verbalized her understanding and agreement of the disputation process, however, her para-verbal communication conveyed a somewhat uncertain undertone. Zara became uncomfortable and teary during one session. Indeed, it is common for clients to harbor doubts during the disputation process, so it was important for the practitioner to elicit and collaboratively address these doubts (Dryden \& Neenan, 2015). Zara voiced her concerns that releasing this dogmatic demand for success would reduce her motivation towards archery; this was particularly poignant because for Zara her determination was an 
attribute she saw as her main strength. This is a common misconception of REBT, where

clients implicitly conclude that through abandoning rigid and dogmatic beliefs this will reduce their motivation to overcome adversity and reach their intended goal, this being incorrectly associated with promoting a philosophy of indifference (Dryden \& Branch, 2008). Instead, the new RBs rather than softening the importance of the adversity facilitated a constructive view of the situation helping them to achieve their goals (Turner \& Barker, 2014). The meaningful replacement of Zara's demand with a very strong preference became her turning point in the REBT program. Accordingly, a set of new and effective RBs (E) was established: "I really really really want to perform well, but that doesn't mean I have to. If I don't it is not the end of the world. I will feel rubbish, but I can accept that". After two sessions of disputing and replacing her IBs with new RBs Zara was able to comprehend that losing her IBs would not reduce her motivation, instead alleviating a do or die approach, which had been hindering her performances. The following extract was taken from a followup interview outlining her struggle to dispute and quell her motivational concerns.

"You know sayings such as I would love to shoot to my potential but I don't have to, that was difficult for me, to me that almost suggested that you might as well not try, but that's not what it meant. That's when we added an extra part to the sentence, I struggled to get my head around it, it was like climbing a mountain without the right equipment, I still have the first rational statement laminated in my case for competition".

To reaffirm the new RBs the practitioner asked Zara to attempt to dispute the new beliefs with evidence, logic, and pragmatics. The inevitable failure to dispute the new RBs helps reaffirm the new RBs and extinguish the old IBs. This disputation process was then repeated again with other significant IBs. Using the ABCDE framework, Zara understood that she could largely influence and determine how helpful her emotional and behavioral responses were when encountering adverse situations. To supplement the ABCDE model, REBT provides various impactful methods that can be used to dispute the client's IBs (see Turner \& Barker, 2014; Dryden \& Neenan, 2015). Specifically, with Zara a 'badness scale' 
was used to challenge her awfulizing beliefs and help her gain perspective on the major and minor incidents that she encountered in her life. Zara was asked to place a numerical degree of badness of a series of example adversities onto a scale between 0-100\% (Ellis, Gordon, Neenan, \& Palmer, 1997). The practitioner then provided Zara with a series of sport specific adversities (e.g., missing an arrow in the final) of which she rated highly on the badness scale. Following this, Zara was provided with a series of major adversities (e.g., loss of a loved one) of which she attempted to rate highly on the badness scale. This process eloquently highlighted for Zara that her perceptions about the severity of the situation were disproportionate with reality and a dip in performance was not "the end of the world".

\section{Reinforcement Phase}

The reinforcement phase is typically introduced towards the latter stage of an REBT intervention and can be completed concurrently with the first two phases. First, an important aspect of REBT is to provide homework tasks to help self-reflection and re-affirmation of its principles (Ellis \& Dryden, 1997). Furthermore, cognitive, emotional, and behavioral methods were used to reinforce and internalize Zara's rational philosophy. Cognitive methods involved working through self-help ABCDE worksheets as well as creating rational selfstatements. Incorporating the influential research of Wolpe (1958) REBT utilizes behavioral assignments allowing clients to actively seek and test out their newly developed rational philosophies in challenging situations (Froggat, 2005). In this case, Zara was asked to purposefully approach indoor competitions, where expectations to be successful were high.

Due to the intimate overlap between behavioral, cognitive, and emotive methods (Ellis, 2004), this assignment allowed Zara to cognitively (e.g., "my performance scores dropped a bit, but it wasn't awful") and emotionally (e.g., "It didn't feel like the end of the world, just annoyed") dispute her irrational philosophy with logic, evidence, and pragmatics, as well as overcoming avoidance tendencies associated with anxiety. 
As the intervention progressed it was important to gauge how Zara's shift in beliefs impacted upon her well-being and performance (Turner \& Barker, 2014). During what would be our last session together $\left(7^{\text {th }}\right)$, the practitioner and Zara were able to discuss and reflect upon the previous six sessions. Zara cited that "it seems ridiculous now looking back at my previous beliefs", as well as noting she felt very positive about her archery and was enjoying it a lot more. Whilst, facilitating positive affect is not the primary objective for REBT, it encourages the client to abandon self-rating and self-esteem, in its place endorsing Unconditional Self-Acceptance (USA; Chamberlain \& Haaga, 2001). USA is defined as "the individual fully and unconditionally accepting themselves whether or not they behave intelligently, correctly, or competently, and whether or not other people approve, respect, or love them" (Ellis, 1977, p. 101). The combination of abandoning self-rating and accepting herself as a fallible human being may explain why Zara's enjoyment of archery improved. Additionally, in line with Self-determination Theory (SDT; Ryan \& Deci, 2000) Zara's shift from a 'have to' to 'want to' was likened to a self-determined motivation, a state manifesting in greater interest, excitement, confidence, and performance (Ryan \& Deci, 2000). was encouraged to become self-sufficient in managing her emotions and behaviors in any situation. A useful method to gauge and reassert Zara's understanding of REBT was through 'Rational Reverse Role-play’ (RRR; Kassinove \& Digiuseppe, 1975). Here the practitioner became the client who role-played an athlete with IBs, whilst Zara acting as the practitioner actively elicited, disputed, and replaced the IBs with new effective RBs. During the seventh and final session it was evident that Zara had made substantial progress, explicitly reporting that she was increasingly able to manage challenging situations and that she no longer required routine one-to-one sessions, instead feeling independent and capable in managing from there onwards. It was then mutually agreed that no further sessions would be necessary 
unless Zara requested additional support. Whilst communication was maintained for a period of two months, no further REBT sessions were completed. REBT provides both a pro-active and re-active framework. In the case of Zara, REBT provided a brief therapy (Ellis, 2013), focused on dealing with and resolving Zara's specific issues. In cases where deeper problems exist a longer program can be provided.

\section{Structured Intervention}

To ascertain intervention effects, self-report and performance scores were collected throughout the intervention and at follow-up time points. To provide social validity, a semi-structured interview was conducted with Zara at the end of the REBT program (Page \& Thelwell, 2013). Questions were oriented around changes in dependent variables, the intervention process, and objective archery performance (Hrycaiko \& Martin, 1996). To monitor changes in Zara's IBs, the SGABS (Lindner et al., 1999) was administered at pre-, middle, post-intervention, and at a three and six month follow-up time points (see Figure 2). Using the SGABS, Zara reported meaningful short and long-term increases in her RBs and decreases in her IBs. REBT theory posits that RBs and IBs are not bi-polar constructs (e.g., high IBs does not signify low RBs; David, Lynn, \& Ellis, 2010). Overlapping with the disputation phase, Zara reported increases in RBs simultaneously with decreases in IBs between sessions one to five. This long-term maintenance supports the successful application of REBT, guiding Zara from an irrational to a rational philosophy. Such a shift was reflected in the following transcript:

"I wasn't convinced at the beginning that you could help. I followed what you said to the letter, slowly I was surprising myself, my mind-set was changing as well as improving my scores as I went along. I wasn't as anxious when little issues arose I had those little statements which I carried which helped a lot." 
IBs are detrimental for psychological well-being, yet within elite sport some consider IBs to possess motivational qualities (Turner \& Barker, 2014). To investigate this matter, analysis of social validation interview indicated that Zara's motivation for archery had been maintained, notably highlighting she had been enjoying competition a lot more. The motivational effect of REBT can be exampled in the following extract:

"I know I am a good archer, now I am physically fit, my style is excellent and my head is now in the right place, because of everything we have worked through, I do have a more relaxed attitude towards archery, which is benefiting my scores greatly and I can put everything negative that happens in the right perspective and minimize the gravity if you like. It helps me to recover better and I'm just more chilled, and to do a good shot you have to be relaxed; it hasn't effected my motivation and that was a big scare that it might".

Zara's strength of efficacy beliefs and perception of control scores across 10

performance markers were reported on a scale between 1 (cannot do at all) and 100 (highly certain can do) on a session-by-session basis (Bandura, 2006). These markers included shot accuracy, focus, shooting consistency, shooting control, appropriate shot timing, remaining strong throughout the shot, maintaining composure, producing one continuous movement for shots, maintaining shooting position, and performing to potential. Zara reported meaningful short and long-term improvements in self-efficacy and perceptions of control across all 10 markers (see Figure 3). Zara's successful adoption of a rational philosophy, (i.e., the formation of functional emotions and behaviors) led to greater emotional control and behavioral functioning. Therefore, in line with the three-dimensional model (Cheng et al., 2009), it was postulated that Zara's enhanced emotional control led to greater perceived control in coping and attaining goals when under stress, in turn, supporting the adaptive vs. maladaptive distinction in negative emotions as proposed by REBT theory. In line with Bandura's taxonomy, an individual's emotional state is proposed to be a key source of self-efficacy. As a result of the REBT intervention, we hypothesized that 
increases in emotional control facilitated Zaras self-efficacy beliefs towards archery performance. Accordingly, developments in both self-efficacy and perceived control were coupled with meaningful and long-term improvements in Zara's archery performances. Zara recorded a $9.24 \%$ increase in average percentage of maximum performance scores between nine pre-intervention competitions $(\mathrm{M}=75.64, \mathrm{SD}=.09)$ and nine post-intervention competitions $(\mathrm{M}=84.88, \mathrm{SD}=.05)$ (see Figure 4). We propose that such improvements in performance provided Zara with experiences of successful previous accomplishments, an important source of self-efficacy subsequently, reinforcing the reciprocal nature of Zara's efficacy beliefs and performance scores (Bandura, 1997).

The precise influence of IBs on control, self-efficacy, and athletic performance has received negligible attention within the extant literature. While this case provides tentative postulations, further laboratory-based research is required to understand the precise effects of REBT on performance. This case study adds to the extant research supporting the use of REBT as an appropriate and effective approach for sport psychologists to use with athletes who present with high IBs. However, to allow for causal and more reliable conclusions to be drawn, future researchers should consider adopting applied research methods characteristic of single-case research (Barker, McCarthy, Jones \& Moran, 2011). To illustrate, single-case designs ensure provision of an individualized intervention, allowing for the onset of the intervention and meaningful changes in the dependent variables to be compared against stable and representative baseline data (Hrycaiko \& Martin, 1996); in turn, the precise effects of REBT would be more accurately discernable.

\section{Considerations for Practitioners}

For practitioners the $\mathrm{ABCDE}$ framework central to REBT is seemingly simple to comprehend and both logical and linear within its application. However, it would be recommended for practitioners considering this approach to gain a broad theoretical and 
applied understanding (e.g., primary practicum in REBT) before adopting REBT within their practice. When contemplating the use of REBT practitioners are recommended to consider a sufficient timescale (5-12 sessions) when providing clients with enough time to understand, practice and re-affirm the principles of REBT (see Turner \& Barker, 2014). It is important to consider the pace and not overwhelm the client. This can be monitored through on-going collaborative reflections and reviews of the client's progress. (Grant, Townsend, Mills, \& Cockx, 2009). When applying REBT the practitioner should manage misconceptions of REBT, mainly the misinterpretation that individuals should adopt a stoic approach; that is an emotionless and indifference to their predicament or the situation. REBT does not withdraw negative emotions in response to adversity, instead encourages a helpful and adaptive response. The process of reaffirming an individual new effective RB's requires long term diligence from the client, where at the beginning REBT assumes an educational approach, progressively the practitioner is encouraged to adopt a collaborative client centered approach (Dryden \& Neenan, 2015). This point is illustrated in the following extract:

"I don't feel lost without you which is good, although I know that you are at the end of the telephone or email and I have my file with all my resources in. In times of doubt I go through that, and reinforce that stuff we done together. I have my little sayings, you know hesitance has ways of creeping back in so it was important to keep my mind strong...these bouts of anxiety seems so long ago, it seems like we have made such large leaps."

\section{Conclusion}

This case study documents the application of an REBT program and its short and long term effects on an elite level archer. This study provides an insight into common misconceptions, challenges and guidance for practitioners who may consider adopting it within their practice. Supporting its core hypothesis it is clear that the case has shown REBT to be a potentially effective psychological intervention to manage IBs and develop sporting performance, allowing the athlete to manage and respond adaptively to adversities that they will inevitably encounter. The maintenance effects found across all dependent variables 
474

475

476

477

478

479

480

481

482

483

484

485

486

487

488

489

490

491

492

493

494

495

496

497

498

demonstrate how REBT targets the root of unhealthy and dysfunctional responses to adversity, thus providing potentially long lasting and curative effects. Whilst not claiming to be a panacea for all issues athletes may encounter, REBT is elegant in that the framework can be used across all aspects of life, and not simply limited to sport. Avenues for future investigation include exploration of the effect of REBT on athletes' motivational approach to their sport, as well as its influence on positive affect. Additionally, in future, researchers may wish to explore the effect of REBT used in conjunction with other psychological approaches and techniques to further facilitate its effect. For example Personal-Disclosure MutualSharing and REBT can be utilized within group settings (PDMS; Dunn \& Holt, 2004), the use of Motivational Interviewing techniques (MI; Rollnick \& Miller, 1995) could be implemented to strengthen clients' motivation for change, and finally elements of positive psychology (Seligman, 2012) could be adopted to actively promote positive affect within the client. 


\section{References}

Bandura, A. (1997). Self-efficacy: The exercise of control. New York: Freeman.

Bandura, A. (2006). Guide for constructing self-efficacy scales. In F. Pajares \& T. Urdan (Eds.), Self-efficacy beliefs of adolescents (pp. 307-337). Greenwich, Connecticut: Information Age Publishing.

Bernard, M.E. (1985). A rational-emotive mental training program for professional athletes. In A. Ellis \& M.E. Bernard (Eds.), Clinical applications of rational-emotive therapy (pp. 227-309). New York: Plenum.

Barker, J., McCarthy, P., Jones, M., \& Moran, A. (2011). Single Case Research Methods in Sport and Exercise. Oxon: Routledge.

Botterill, C. (2005). Competitive drive: Embracing positive rivalries. In S. Murphy (Ed.), The sport psych handbook (pp. 37-48). Champaign, IL: Human Kinetics.

Chamberlain, J. M., \& Haaga, D. A. (2001). Unconditional self-acceptance and psychological health. Journal of Rational-Emotive and Cognitive-Behavior Therapy, 19, 163-176. 10.1023/A:1011189416600.

Cheng, W. N. K., Hardy, L., \& Markland, D. (2009). Toward a three-dimensional conceptualization of performance anxiety: Rationale and initial measurement development. Psychology of Sport and Exercise, 10, 271-278. doi:10.1016/j.psychsport.2008.08.001

David, D., Lynn, S. J., \& Ellis, A. (Eds.). (2010). Rational and irrational beliefs: Research, theory, and clinical practice (pp. 339-348). Oxford: Oxford University Press.

David, D., Szentagotai, A., Eva, K., \& Macavei, B. (2005). A synopsis of rational-emotive behavior therapy (REBT); fundamental and applied research. Journal of RationalEmotive and Cognitive-Behavior Therapy, 23, 175-221. doi: 10.1007/s10942-0050011-0 
524

525

526

527

528

529

530

531

532

533

534

535

536

537

538

539

540

541

542

543

544

545

546

DiGiuseppe, R. (1991). Maximizing the moment: How to have more fun and happiness in life. Cassette recording. New York: Institute for Rational Emotive Therapy.

DiGiuseppe, R. A., Doyle, K. A., Dryden, W., \& Backx, W. (2013). A Practitioner's Guide to Rational-Emotive Behavior Therapy. Oxford University Press.

Dryden, W. (2002). Rational emotive behaviour therapy; a reader. London: SAGE.

Dryden, W. (2009). How to think and intervene like an REBT therapist. London: Routledge.

Dryden, W., \& Branch, R. (2008). Fundamentals of rational emotive behaviour therapy: A training handbook. Chichester: John Wiley \& Sons.

Dryden, W., \& Neenan, M. (2015). Rational emotive behaviour therapy: 100 key points and techniques. Hove: Routledge.

Dunn, J. G., \& Holt, N. L. (2004). A qualitative investigation of a personal-disclosure mutual-sharing team building activity. The Sport Psychologist, 18, 363-380.

Elko, K. P., \& Ostrow, A. C. (1991). Effects of a rational-emotive education program on heightened anxiety levels of female collegiate gymnasts. The Sport Psychologist, 5, 235- 255.

Ellis, A. (1957). Rational psychotherapy and individual psychology. Journal of Individual Psychology, 13, 38-44.

Ellis, A. (1977). Psychotherapy and the value of a human being. In A. Ellis \& R. Grieger (Eds.), Handbook of rational-emotive therapy (pp. 99-112). New York: Springer.

Ellis, A. (2013). Better, deeper and more enduring brief therapy: The rational emotive psycholbehavior therapy approach. Routledge: Bruner/Mazel Inc.

Ellis, A., \& Dryden, W. (1997). The practice of rational-emotive behavior therapy. NewYork: Springer Publishing Company. 
547

548

549

550

551

552

553

554

555

556

557

558

559

560

561

562

563

564

565

566

567

568

569

570

Ellis, A., Gordon, J., Neenan, M., \& Palmer, S. (1997). Stress: A rational emotive behavior approach. London: Cassell.

Ellis, A. (2004). Why rational emotive behavior therapy is the most comprehensive and effective form of behavior therapy. Journal of Rational-Emotive \& CognitiveBehavior Therapy, 22, 85-92. doi:10.1023/B:JORE.0000025439.78389.52

Engles, G. I., Garnefski, N., \& Diekstra, R. F. W. (1993). Efficacy of rational emotive therapy: A quantitative analysis. Journal of Consulting and Clinical Psychology, 61, 1083-1090. doi:10.1037/0022-006X.61.6.1083

Epictetus (1948). The Enchiridion. Indianapolis: Bobbs-Merrill. Gordon, R. M. 1987. The Structure of Emotions. Cambridge: Cambridge Univ. Press.

Froggatt, W. (2005). A brief introduction to rational emotive behavior therapy. From http://www.rational.org.nz/prof- docs/Intro-REBT.pdf

Giges, B., \& Van Raalte, J. (2012). Special issue of The Sport Psychologist case studies in sport psychology introduction. The Sport Psychologist, 26, 483-485.

Grant, A., Townend, M., Mills, J., \& Cockx, A. (2009). Assessment and case formulation in Cognitive Behavioural Therapy. London: Sage.

Hrycaiko, D., \& Martin, G. L. (1996). Applied research studies with single-subject designs: Why so few? Journal of Applied Sport Psychology, 8, 183-199. doi:10.1080/10413209608406476

Hyland, P., \& Boduszek, D. (2012). A unitary or binary model of emotions: A discussion on a fundamental difference between cognitive therapy and rational emotive behaviour therapy. Journal of Humanities and Social Sciences, 1, 49-61.

Kassinove, H., \& DiGiuseppe, R. (1975).Rational role reversal. Rational Living, 10(1), 4445. 
571

572

573

574

575

576

577

578

579

580

581

582

583

584

585

586

587

588

589

590

591

592

593

Larner, C., Morris, T., \& Marchant, D. (2007, September). The management of directional trait anxiety in competitive sports with rational-emotive behavior therapy. Paper Presented at the European Congress of Sport Psychology. Retrieved from http:// vuir.vu.edu.au/2048

Lazarus, R.S. (1991). Progress on a cognitive-motivational- relational theory of emotion. The American Psychologist, 46(8), 819-834. doi:10.1037/0003-066X.46.8.819

Lindner, H., Kirkby, R., Wertheim, E., \& Birch, P. (1999). A brief assessment of irrational thinking: The shortened general attitude and belief scale. Cognitive Therapy and Research, 23, 651-663. doi:10.1023/A:1018741009293

Lyons, L. C., \& Woods, P. J. (1991). The efficacy of rational-emotive therapy: A quantitative review of the outcome research. Clinical Psychology Review. 11, 357-369. doi $10.1016 / 0272-7358(91) 90113-9$

Neenan, M., \& Dryden, W. (2004). Cognitive therapy: 100 key points and techniques. Hove: Routledge.

Peterson, Z. D. (2002). More than a mirror: The ethics of therapist self disclosure. Psychotherapy: Theory, Research, Practice, Training, 39(1), 21. doi:10.1037//0033-3204.39.1.21

Pitt, T., Lindsay, P., Thomas, O., Bawden, M., Goodwill, S., \& Hanton, S. (2015). A perspective on consultancy teams and technology in applied sport psychology. Psychology of Sport and Exercise, 16, 36-44. doi:10.1016/j.psychsport.2014.07.002

Rollnick, S., \& Miller, W. R. (1995). What is motivational interviewing? Behavioural and Cognitive Psychotherapy, 23(04), 325-334. doi:10.1017/S135246580001643X 
594

595

596

597

598

599

600

601

602

603

604

605

606

607

608

609

610

611

612

613

614

615

616

617

Ryan, R. M., \& Deci, E. L. (2000). Self-determination theory and the facilitation of intrinsic motivation, social development, and well-being. The American psychologist, 55(1), 68. doi:10.1037/0003-066X.55.1.68

Seligman, M. E. (2012). Flourish: A new understanding of happiness and well-being - and how to achieve them. London: Nicholas Brealey Publishing.

Sultanoff, S. M. (2013). Integrating Humor Into Psychotherapy: Research, Theory, and the Necessary Conditions for the Presence of Therapeutic Humor in Helping Relationships. The Humanistic Psychologist, 41, 388-399. doi:10.1080/08873267.2013.796953

Turner, M. J. (2014). Smarter thinking in sport. The Psychologist, 27, (8), 596-599.

Turner, M. J., \& Barker, J. B. (2014). Using rational emotive behavior therapy with athletes. The Sport Psychologist, 28, 75-90. doi:10.1123/tsp.2013-0012

Turner, M.J., Slater, M.J., \& Barker, J.B. (2014a). Not the end of the world: The effects of rational emotive behavior therapy on the irrational beliefs of elite academy athletes. Journal of Applied Sport Psychology, 26, 144-156. doi:10.1080/10413200.2013.812159

Turner, M. J., Slater, M. J., \& Barker, J. B. (2015). The season-long effects of rational emotive behavior therapy on the irrational beliefs of professional academy soccer athletes [Abstract]. International Journal of Sport Psychology, 5, 429-451.

Weston, N. J., Thelwell, R. C., Bond, S., \& Hutchings, N. V. (2009). Stress and coping in single-handed round-the-world ocean sailing. Journal of Applied Sport Psychology, 21, 460-474. doi:10.1080/10413200903232607

Wolpe, J. (1958).Psychotherapy by reciprocal inhibition. Stanford, CA: Stanford University Press. 


\section{Figure Captions}

620 Figure 1. A schematic of the ABCDE framework used within the REBT process.

621 Figure 2. Shortened General Attitudes and Belief Scale (SGABS) scores taken at session one, 622 mid-point, last session and at a 3 and 6-month follow up time point.

623 Figure 3. Self-efficacy and control scores for 10 archery specific performance markers taken 624 on a session by session and at a 6-month follow up time point.

625 Figure 4. Pre- and Post- Intervention competition performance scores - calculated as 626 percentage of maximum score attainable per competition. 
628
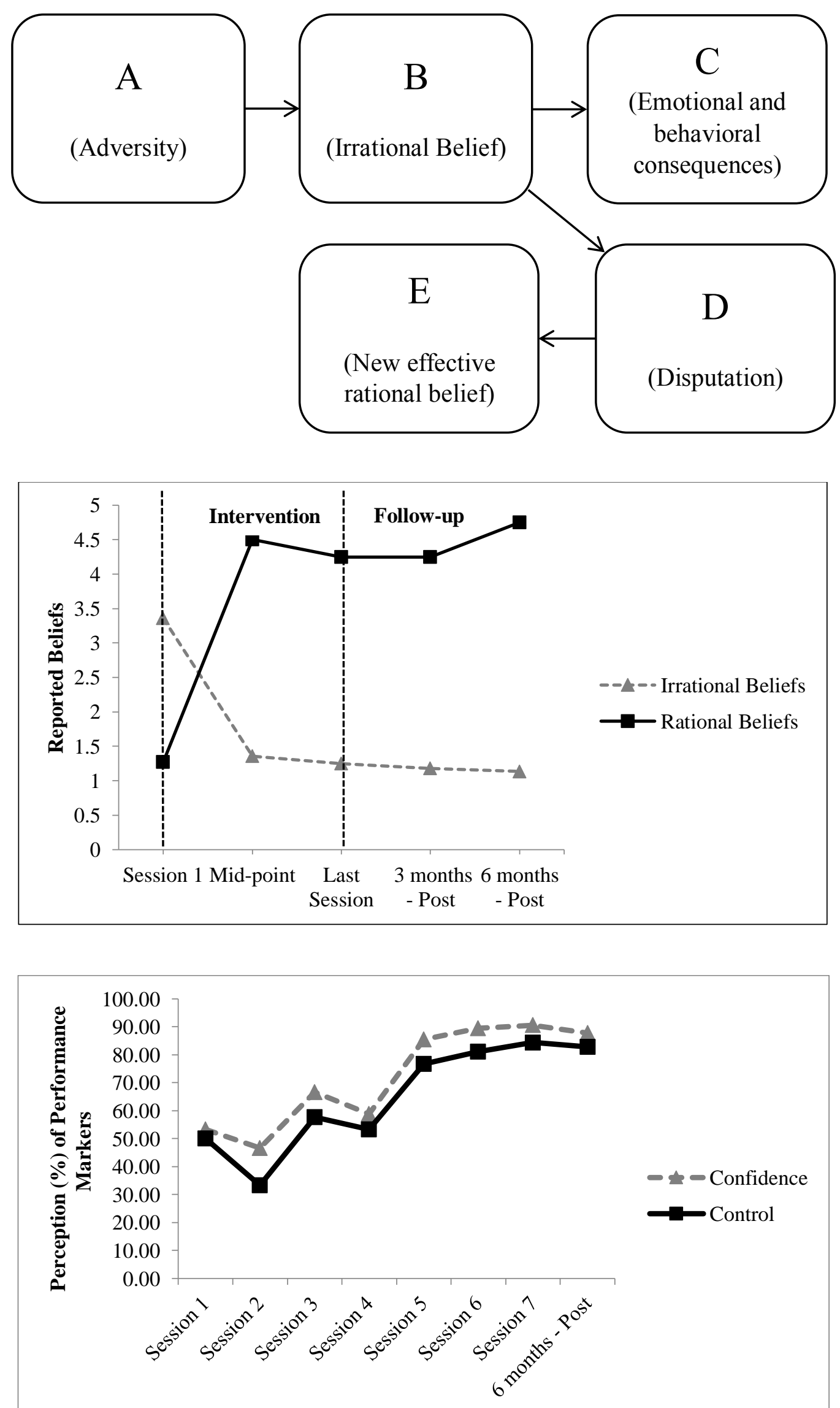


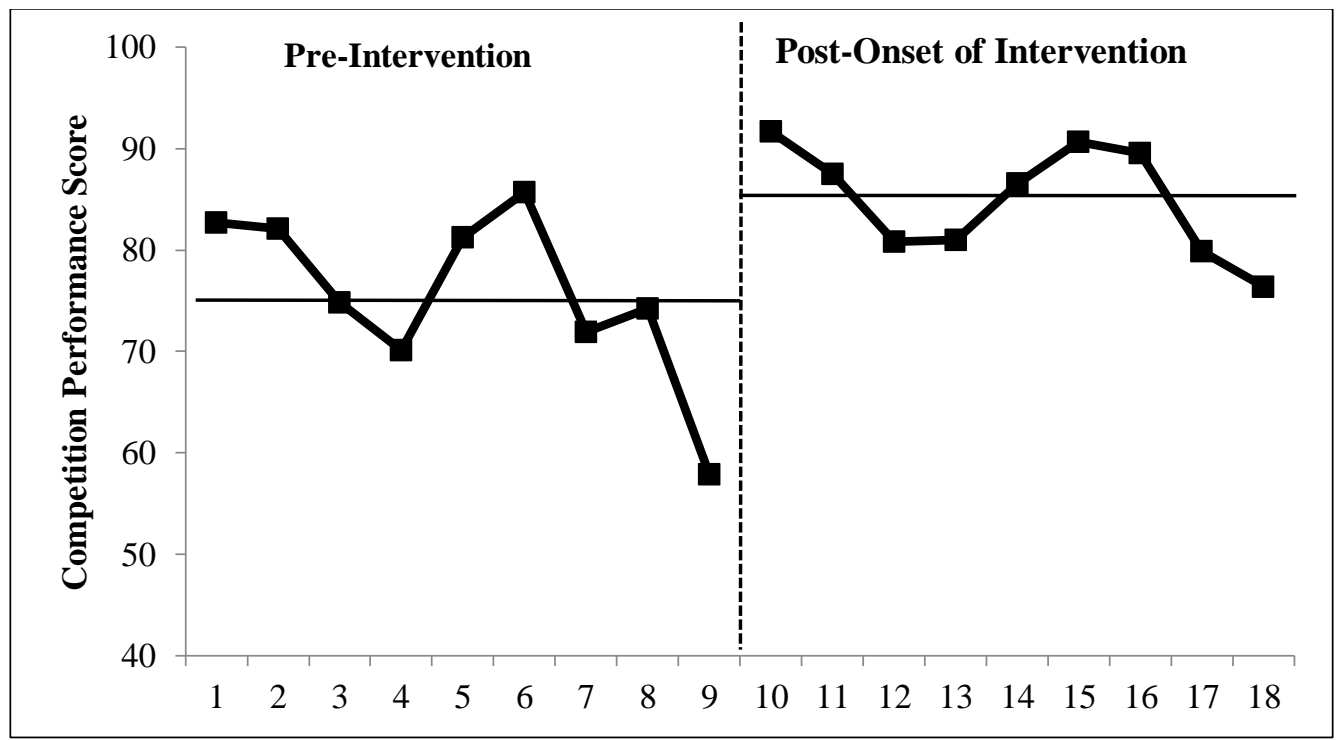

